\title{
Breath Hydrogen Reflects Canine Intestinal Ischemia
}

\author{
JAY A. PERMAN, ${ }^{(32)}$ LAUREL A. WATERS, MICHAEL R. HARRISON, EDWARD S. YEE, AND \\ GREGORY P. HELDT \\ Departments of Pediatrics and Surgery, University of California, San Francisco, San Francisco, California, USA
}

\begin{abstract}
Summary
The relationship between breath hydrogen excretion and intestinal ischemia was investigated in nine mechanically ventilated dogs under pentobarbital anesthesia. An ileal segment was isolated in situ, ligated at each end, and insufflated with hydrogen. Expired air was collected at intervals. Blood volume was reduced $30 \%$ by three successive equivalent hemorrhages $10 \mathrm{~min}$ apart. Local bowel ischemia was produced by clamping the blood supply to the isolated segment for $10 \mathrm{~min}$. Graded hemorrhage produced stepwise reductions in breath hydrogen concentration, to $77 \pm 13,66$ \pm 15 , and $35 \pm 8 \%$ (mean \pm S.E.) of baseline after the first, second, and third hemorrhages, respectively. These reductions correlated highly $(r=0.84 ; P<0.01)$ with declines in mean aortic blood pressure. Occlusion of blood supply caused a significant $(P$ $<0.025)$ decrease in breath hydrogen concentration and excretion to $39 \pm 14 \%$ of baseline. Termination of occlusion was followed within 2 min by a 7-fold increase in breath $\mathrm{H}_{2}$ concentration above the original baseline, probably reflecting reactive hyperemia. Breath hydrogen measurements appear to reflect functional (hemorrhagic shock-induced) and mechanical (vascular occlusion induced) enteric ischemia in dogs.
\end{abstract}

\section{Speculation}

Monitoring of breath $\mathrm{H}_{2}$ excretion in the infant at risk for necrotizing enterocolitis may indicate the development of enteric hypoperfusion. Inhibition of transfer of $\mathrm{H}_{2}$ into the portal circulation in the presence of reduced mesenteric blood flow may contribute to distention of the bowel in necrotizing enterocolitis and further impede intestinal perfusion.

Exhaled hydrogen $\left(\mathrm{H}_{2}\right)$ is an accurate, noninvasive index of intestinal carbohydrate malabsorption, $(6,12,13,17,18,20) . \mathrm{H}_{2}$ in breath is the product of: (1) incomplete absorption of sugar substrate; (2) intraluminal fermentation of substrate by enteric flora yielding $\mathrm{H}_{2}$; (3) transfer of $\mathrm{H}_{2}$ into the portal circulation; (4) perfusion of the lungs resulting in diffusion of $\mathrm{H}_{2}$ into the air spaces; and (5) excretion of $\mathrm{H}_{2}$ from the alveoli. Although the availability of carbohydrate and bacteria governs production of $\mathrm{H}_{2}$, the transfer of $\mathrm{H}_{2}$ from the intestinal lumen to the lung appears to be dependent on circulatory factors. By fitting absorption parameters for inert gases to models of interaction between perfusion and diffusion, Levitt and Levitt (14) demonstrated that the rate of absorption of $\mathrm{H}_{2}$ from the intestine is primarily a function of intestinal blood flow, being only marginally affected by diffusion. Enteric perfusion being the rate-limiting step in absorption of hydrogen, changes in intestinal blood flow sufficient to produce ischemia should be reflected in breath $\mathrm{H}_{2}$ excretion. The purpose of the present study was to determine the effects of functional (hemorrhagic shock-induced) and mechanical (vascular occlusioninduced) reduction in intestinal perfusion on $\mathrm{H}_{2}$ excretion in breath.
MATERIALS AND METHODS

\section{PREPARATION OF INTESTINAL SEGMENTS}

Transfer of $\mathrm{H}_{2}$ from the intestinal lumen to alveolar air was measured using closed intestinal segments prepared in situ in anesthetized dogs. Eight adult mongrel dogs and a 1-week-old puppy were premedicated with xylazine ( $30 \mathrm{mg} \mathrm{IM}$ ) and anesthetized with pentobarbital $300 \mathrm{mg}$ IV. After intubation, anesthesia was maintained with pentobarbital at a level that allowed control of ventilation by a volume-regulated Harvard pump. Catheters were placed in the femoral arteries, and blood presssure was continuously recorded via arterial catheter attached in series to a transducer and strip chart recorder. Respiratory rate and volume were adjusted to establish a normal initial arterial $\mathrm{Po}_{2}, \mathrm{PCO}_{2}, \mathrm{pH}$ and minute ventilation. These values did not change significantly during the experimental period. A midline abdominal incision was made, and a segment of ileum approximately $45 \mathrm{~cm}$ in length was isolated by ligating the segment proximally and distally with umbilical tape. The ileal segments selected for study were supplied by a single, easily identifiable mesenteric vascular arcade. A 20 gauge Teflon catheter with inner needle stylet tunneled through the intestinal wall and sealed with a purse string suture was used to instill $100 \% \mathrm{H}_{2}$ into the lumen of the isolated segment. Distention of the bowel was minimized to prevent limitation of blood flow by compression. The volume required to insufflate segments without undue distention ranged between 50 and $100 \mathrm{ml}$.

In one animal subjected to vascular clamping, tissue oxygen was measured with Teflon membrane Medspect catheters (Scientific Research Instruments Corp., Baltimore, MD) tunneled through the enteric wall into the submucosa. The Medspect sampling catheter consists of a teflon tip which is formed to provide a diffusion chamber (28). One catheter was placed in the isolated loop and a control catheter in an adjacent segment of normally perfused intestine. Tissue $\mathrm{PO}_{2}$ values recorded by these catheters were quantified with a Medspect Medical Mass Spectrometer.

\section{BREATH HYDROGEN}

Expired air was collected for $30 \mathrm{sec}$ at 2- to 3-min intervals into weather balloons via a nonrebreathing valve. Volumes were measured with a 1.5 liter syringe attached to a pressure gauge which maintained atmospheric pressure. Aliquots of expired air were immediately drawn into plastic syringes equipped with three-way stopcocks. Samples were analyzed within $8 \mathrm{hr}$ or stored in Vacutainers for subsequent assay. Stability of samples using this methodology has been previously established (20). $\mathrm{H}_{2}$ was measured on a gas chromatograph (Carle Instruments, Fullerton, CA) equipped with a thermistor detector. Ten $\mathrm{ml}$ samples were applied to a molecular sieve column at $25^{\circ} \mathrm{C}$ using zero grade argon as the carrier gas. Peak height was measured, and concentrations determined by comparison with known standards (Liquid Carbonic, San Carlos; CA). The minimum detectable concentration of $\mathrm{H}_{2}$ was $0.5 \mu \mathrm{mol}$ ( $1 \mathrm{part} /$ million). $\mathrm{H}_{2}$ excretion rate was calculated 
from the product of $\mathrm{H}_{2}$ concentrations and total volume of gas excreted per timed collection.

\section{EXPERIMENTAL PROCEDURES}

To demonstrate stability of hydrogen excretion during periods free from systemic or local manipulation of intestinal perfusion, two dogs were sampled for periods of $40 \mathrm{~min}$ after insufflation of gas. Each series of manipulations described below was completed within $40 \mathrm{~min}$ of insufflation.

\section{REDUCTION IN MESENTERIC PERFUSION INDUCED BY ACUTE HEMORRHAGE}

Four dogs and the pup were deprived of $30 \%$ of total blood volume, removed in three equal increments by withdrawal through a femoral artery catheter at 10 -min intervals. Blood volume was estimated at $8 \%$ of body weight. Mean blood pressure was calculated from the strip chart tracing by the formula: $\frac{S+2 D}{3}$ where $\mathrm{S}$ is systolic and D diastolic blood pressure (26).

\section{REDUCTION IN MESENTERIC PERFUSION INDUCED BY VASCULAR OCCLUSION}

Four dogs underwent occlusion of blood supply to the isolated bowel loop by application of vascular clamps to the artery and vein in two dogs and the artery only in two dogs. Occlusion was maintained for $10 \mathrm{~min}$. The two methods of mechanical vascular obstruction produced comparable results which were, therefore, combined. Obstruction of blood supply was evidenced by the visual appearance of the bowel, and in one animal, by tissue $\mathrm{PO}_{2}$ levels monitored with the mass spectrometer.

Average values from determination during each baseline and experimental period are used for analysis. Preliminary experiments indicated that stable breath hydrogen and blood pressure levels were maintained for a minimum of $9 \mathrm{~min}$ after a $1 \mathrm{~min}$ equilibration period which followed insufflation of ileal segments. However, there were biologic variations between animals in postinsufflation breath hydrogen and blood pressure levels. For comparison among animals, data are therefore normalized as percent of postinsufflation baseline value in each animal.

\section{RESULTS}

$\mathrm{H}_{2}$ concentration in breath of fasting animals before insufflation averaged (mean \pm S.E.) $3.5 \pm 1.2 \mathrm{ppm}$, rising to $13.8 \pm 3.8 \mathrm{ppm}$ after insufflation of $100 \% \mathrm{H}_{2}$ into isolated segments. $\mathrm{H}_{2}$ concentrations in breath of individual animals were remarkably stable during control periods following insufflation. Thus, breath $\mathrm{H}_{2}$ in two dogs left undisturbed for $40 \mathrm{~min}$ averaged $11.5 \pm 0.6 \mathrm{ppm}$ (17 determinations) and $26.4 \pm 2.3$ (six determinations), respectively.

Successive bleedings induced consistent declines in $\mathrm{H}_{2}$ excretion which paralleled the decrease in blood pressure in all animals, including the single immature animal (Fig. 1). $\mathrm{H}_{2}$ concentrations in breath averaged $77 \pm 13,66 \pm 15$, and $35 \pm 8$ of baseline at 10 , 20 and $30 \%$ decreases in blood volume respectively. Blood pressure averaged $78 \pm 9,61 \pm 10$, and $37 \pm 7 \%$ of baseline during the corresponding periods. The decrease in $\mathrm{H}_{2}$ concentrations with phlebotomy was significant $(P<0.02)$ when blood pressure declined to $70 \%$ of control. One dog (no. 4) appeared relatively resistant to the effects of hemorrhage. A $10 \%$ reduction in blood volume failed to induce changes in either $\mathrm{H}_{2}$ or blood pressure. The blood pressure decreased slightly when $20 \%$ of the total blood volume was removed, but the mean $\mathrm{H}_{2}$ remained stable. The relatively large standard deviation in this measurement was due to declining $\mathrm{H}_{2}$ values in the last part of the period. This was the largest $\operatorname{dog}(25 \mathrm{~kg})$ in the series, and estimation of total blood volume may not have been accurate in this animal. The relationship between breath $\mathrm{H}_{2}$ and blood pressure in dogs is shown in Figure 2. The correlation coefficient between the two measurements was $0.84(P<0.01)$.

Breath $\mathrm{H}_{2}$ excretion decreased after occlusion of mesenteric blood supply in a manner analagous with the response induced by blood loss (Fig. 3). Mean breath $\mathrm{H}_{2}$ concentrations for the four mature animals declined to $39 \pm 14 \%$ of baseline (range, 6 to $71 \%$ of baseline) during the clamping period, yielding identical results when expressed either in terms of $\mathrm{H}_{2}$ concentration (ppm) or excretion $(\mathrm{cc} / \mathrm{min})$. Hydrogen concentrations before and during the obstruction of blood supply differed significantly $(P<0.025)$. Release of the clamp resulted in a rapid 7 -fold increase in $\mathrm{H}_{2}$ concentration during the first $3 \mathrm{~min}$ after unclamping $(P<0.025)$ and a more gradual decline toward preclamping values during the subsequent $12 \mathrm{~min}$.

The degree of ischemia during the clamping and during the recovery period after release of the clamp, was monitored with tissue $\mathrm{PO}_{2}$ measurements in one dog. The progressive decline in $\mathrm{H}_{2}$ excretion recorded during the ischemic phase was paralleled by a reduction in tissue $\mathrm{PO}_{2}$ from 30 to 3 torr followed by a gradual rise to 28 torr during recovery. Tissue $\mathrm{Po}_{2}$ values in the control segment ranged between 33 and 42 torr during the entire experiment.

$\begin{array}{lllccc}\text { Dog.\# } & 1 & \underline{2} & \underline{3} & \underline{4} & \underline{\text { Pup }} \\ \text { Baseline } H_{2} \text { (ppm) } & 21.8 & 5.1 & 15.3 & 12.6 & 24.4 \\ \text { Baseline Mean B.P. } & 62 & 110 & 107 & 130 & 46\end{array}$

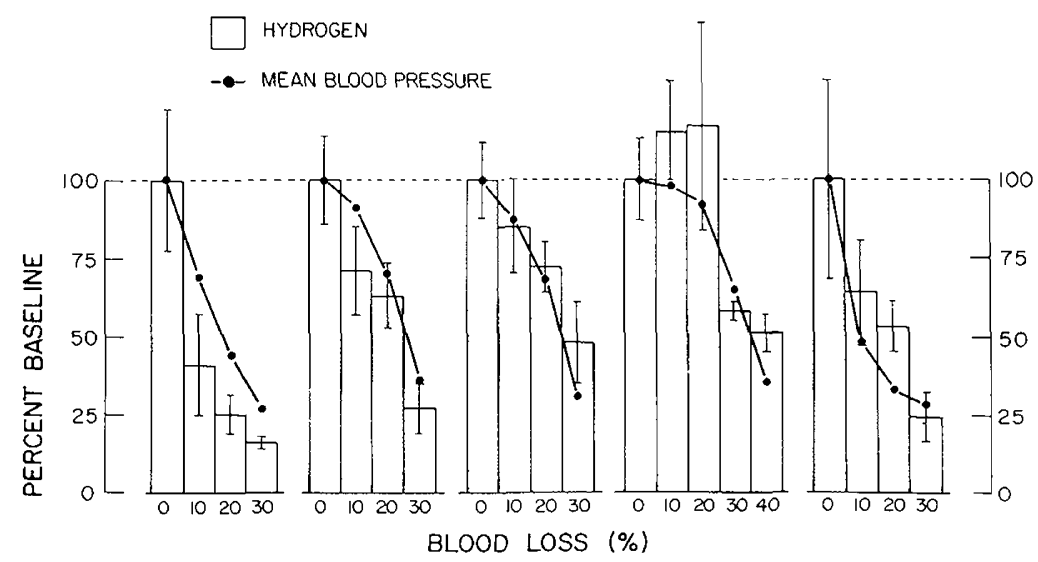

Fig. 1. Effect of blood loss on breath $\mathrm{H}_{2}$ and blood pressure. Mean $\mathrm{H}_{2}$ concentrations \pm S.D. in expired air and mean blood pressures obtained in five dogs subjected to graded hemorrhage (10\% decrements) are expressed as percentages of the initial values (tabulated above each set of bars). Bars represent the average of two to six samples of $\mathrm{H}_{2}$ obtained during the 10 -min interval between each blood drawing. interval. 


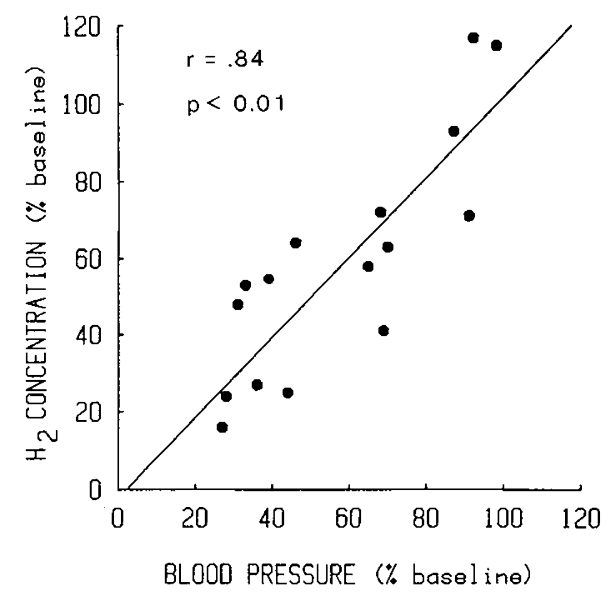

Fig. 2. Correlation of breath $\mathrm{H}_{2}$ and blood pressure after blood loss. Equation of the line is $y=1.04 x-2.40$. Baseline values are not included.

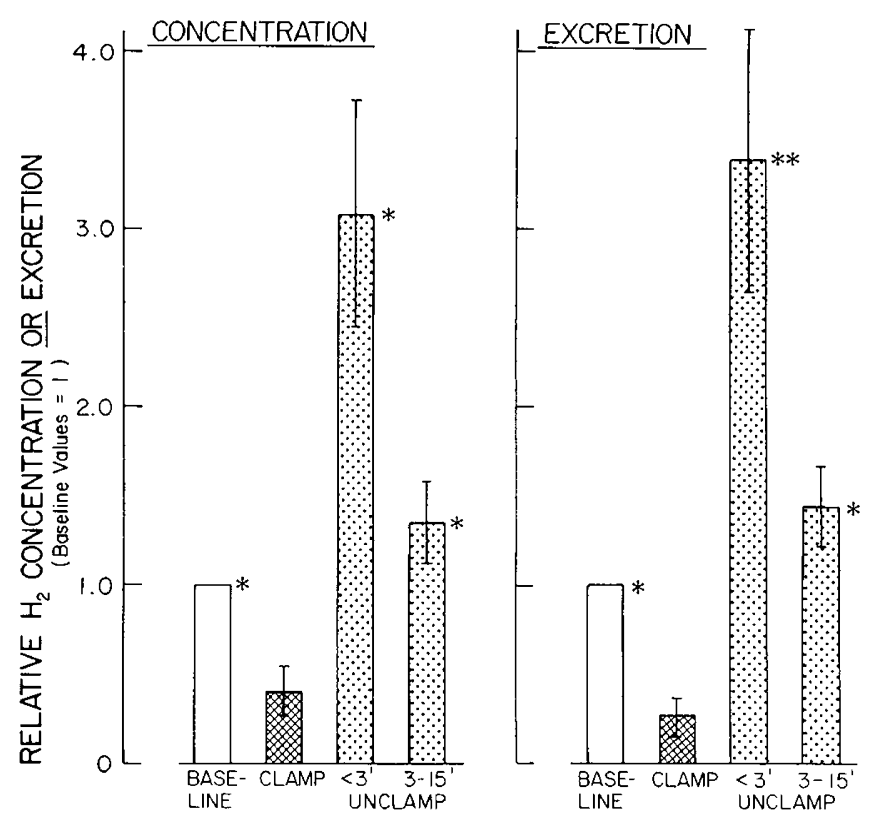

Fig. 3. Effect of local mesenteric vascular clamping on breath $\mathrm{H}_{2}$ concentration (left panel, four dogs) and breath $\mathrm{H}_{2}$ excretion [right panel, three dogs (expired air volume was not measured in one dog)]. Excretion was calculated from the product of $\mathrm{H}_{2}$ concentration and total volume of gas excreted per timed collection. Bars \pm S.D. represent average multiples of baseline $\mathrm{H}_{2}$ (open bars) during the 10 -min period of occlusion (crosshatched bars) and the periods after relief of occlusion (stippled bars). Values obtained during the clamp period were compared with values from baseline and postocclusion periods by the paired $t$ test. $\left({ }^{*}, P<0.025 ;{ }^{* *}\right.$, $P<0.05)$

Interruption of blood supply by vascular occlusion was rapidly reflected in discoloration of the affected intestinal segment. Conversely, removal of the clamp was followed within seconds by a deep red blush of the bowel wall.

\section{DISCUSSION}

The $\mathrm{H}_{2}$ content in breath depends on availability of fermentable substrate, $\mathrm{H}_{2}$-producing intestinal bacterial flora, and a transport phase requiring mesenteric blood flow. Previous studies have shown that the quantity and rate of $\mathrm{H}_{2}$ excretion are related to quantity of substrate administered, rate of gastric emptying, small intestinal transit time, and number and types of bacteria present (2). The present study demonstrates that alteration of intestinal perfusion is an additional factor affecting breath $\mathrm{H}_{2}$ excretion. Breath $\mathrm{H}_{2}$ reflects canine intestinal ischemia induced by hemorrhage or occlusion. $\mathrm{H}_{2}$ also reflects the return of perfusion during the hyperemic phase after restoration of flow.

Intestinal ischemia was induced by systemic (hemorrhage) and local (occlusion) manipulations. Although blood flow was not directly measured in the present experiments, reduction in canine splanchnic blood flow by hemorrhagic shock is well established $(7,25)$. For example, in a canine model with hemorrhage at a constant rate of $10 \mathrm{cc} / \mathrm{kg} / \mathrm{hr}$, Smith et al. (25) demonstrated a $27 \%$ decrease in superior mesenteric artery flow after $30 \mathrm{~min}(5 \mathrm{cc} / \mathrm{kg}$ bleed) and $50 \%$ decrease at $90 \mathrm{~min}(15 \mathrm{cc} / \mathrm{kg}$ bleed $)$, corresponding with 4 and $20 \%$ decreases, respectively, in systemic pressure. These observations demonstrate the considerable effect of hemorrhage on intestinal perfusion and establish that hemorrhage significantly decreases mesenteric blood flow in the species studied here. The slower rate of hemorrhage used by Smith et al. compared with the present study $(8 \mathrm{cc} / \mathrm{kg}$ over $10 \mathrm{~min}$ ) may explain the disproportionately high reductions from prehemorrhage values in mesenteric blood flow compared to systemic pressure, thus permitting more time for compensatory mechanisms to maintain systemic pressure. Barton et al. (1) demonstrated in primates that more rapidly induced hemorrhagic shock causes proportionate decreases in systemic arterial pressure and mesenteric artery flow.

Although the correlation between reduction in systemic arterial pressure, indicative of mesenteric hypoperfusion, and breath $\mathrm{H}_{2}$ excretion appeared to be linear in this study, it is recognized that the relationship between passive absorption of luminal gas and blood flow is complex. Bond et al. (3) have demonstrated that the observed absorption of $\mathrm{H}_{2}$ in canines was only $16.2 \%$ of what villus blood flow could carry away if it reached perfect equilibrium with gas in the lumen. This low absorption rate appeared to be due to a very efficient countercurrent exchange of $\mathrm{H}_{2}$ in the mucosal villi. The effect of reduction in mesenteric blood flow on countercurrent exchange and thus net absorption of gas has not been reported. If the efficiency of countercurrent exhange were diminished by reduction in mesenteric blood flow, the net absorption of gas would increase. This would have the effect of blunting the decrease in $\mathrm{H}_{2}$ excretion expected upon reduction of blood flow. However, the observed reductions in $\mathrm{H}_{2}$ excretion, although possibly blunted by a decrease in countercurrent exchange, were nonetheless clear. Alternatively, the efficiency of countercurrent exchange might be enhanced by a reduction in mesenteric blood flow, decreasing net $\mathrm{H}_{2}$ absorption and thereby overestimating the degree of ischemia indicated by declining breath $\mathrm{H}_{2}$ excretion. Thus, the observed changes in $\mathrm{H}_{2}$ excretion after functionally induced ischemia may have been influenced by ischemia-induced alterations in the efficiency of countercurrent exchange. Further investigations are required to evaluate this possibility.

Changes in $\mathrm{H}_{2}$ excretion associated with hemorrhage may also be attributable to the effects of acute blood loss on pulmonary function. Significant blood loss in experimental animals causes an increase in mintute ventilation (15) which would be expected to reduce $\mathrm{H}_{2}$ concentration in expired air. For this reason, minute ventilation was controlled in the present study. Acute hypovolemia in canines also causes a decrease in pulmonary capillary blood volume and in the diffusion capacity for carbon monoxide (4). Therefore, an analagous reduction in the diffusion of $\mathrm{H}_{2}$ into the air spaces after hemorrhage can not be excluded as a potential mechanism for the decrease in breath $\mathrm{H}_{2}$ associated with blood Ioss.

To eliminate the possible influence of alterations in pulmonary function on $\mathrm{H}_{2}$ excretion while decreasing mesenteric perfusion, intestinal ischemia was induced locally by application of vascular clamps. Although prolonged segmental vascular occlusion can have systemic effects (10), Norlen et al. (19) have demonstrated in the rat that occlusion of local mesenteric vessels for a minimum of 30 min does not alter central hemodynamics. Therefore, it is likely that clamping mesenteric blood supply to a limited segment of dog intestine for 10 min would have minimal effects on pulmonary function. Furthermore, changes in breath $\mathrm{H}_{2}$ expressed as excre- 
tion rate after clamping and unclamping are the same as the observed changes in breath $\mathrm{H}_{2}$ expressed as concentration, demonstrating that the observed changes in $\mathrm{H}_{2}$ concentration are not on the basis of changes in ventilation.

Reduction in mesenteric perfusion upon application of clamps was verified by changes in mucosal $\mathrm{PO}_{2}$ as measured by mass spectrometer in one animal and in all animals by observation of color changes of the hypoperfused bowel. The association of color changes with alterations in mesenteric perfusion has previously been established (23); spontaneous increases in recorded blood flow were shown to be associated with reddening and decreased blood flow with paleness of intestine. It should be mentioned that in the present study, a transient and unexplained dusky appearance of the bowel in one animal before the application of clamps was accompanied by a decrease in breath $\mathrm{H}_{2}$ concentration which returned to baseline values when the bowel recovered its normal appearance.

Marked and rapid reddening in appearance of the bowel, associated with a sharp rise in $\mathrm{H}_{2}$ excretion to values far above the baseline period, occurred in all animals after release of the vascular clamps. This phenomenon is probably due to hyperemia which has been noted by Selkurt et al. (24) immediately after relief of occlusion of blood flow to the canine ileum. These investigators also demonstrated that the duration of hyperemia was directly related to the duration of ischemia. Occlusion of blood flow for 5 min resulted in a postocclusion hyperemic phase lasting at least 5 min. These findings may explain the failure of $\mathrm{H}_{2}$ excretion to return to baseline values during the period after relief of occlusion in the present study. Breath $\mathrm{H}_{2}$ correlated well with the bowel appearance under normal, ischemic, and hyperemic conditions, whereas tissue $\mathrm{PO}_{2}$ measurements did not reflect the hyperemic phase.

The persistence of $\mathrm{H}_{2}$ in breath during occlusion may be attributable to continued excretion of endogenously produced $\mathrm{H}_{2}$. Although animals were fasted before study, residual nonabsorbed substrate was present in colon as evidenced by $\mathrm{H}_{2}$ in breath before insufflation of the isolated segment. Because blood flow is increased in segments of bowel distal to ischemic regions (19), it is likely that $\mathrm{H}_{2}$ absorption from the colon was actually enhanced during more proximal occlusion. Despite this potential enhancement which would blunt the observed decrease in breath $\mathrm{H}_{2}$ after occlusion, a significant difference between pre- and postocclusion breath $\mathrm{H}_{2}$ excretion was observed.

Because acute hemorrhage and mesenteric vascular occlusion cause gross reductions in mesenteric blood flow, further investigation is necessary to establish the influence of less drastic changes in intestinal perfusion on breath $\mathrm{H}_{2}$ measurements. Small fluctuations in perfusion could account for the variability of measurements during control and various experimental periods. Such fluctuations in intestinal perfusion have been demonstrated in man undergoing stress (27). It is noteworthy that anxiety has been previously shown to affect breath $\mathrm{H}_{2}$ excretion (5). On the basis of the present study, it may be speculated that the effects of psychologic states on breath $\mathrm{H}_{2}$ may be accounted for by their influence on intestinal blood flow. It is also speculated that hydrogen excretion may be dampened in patients with intestinal hypoperfusion, potentially affecting the results and interpretation of clinical breath tests for carbohydrate malabsorption.

The selection of ileal segments for study was dictated by the frequent involvement of the ileum and colon in necrotizing enterocolitis of neonates, especially those born prematurely. Although the cause of this disorder remains unknown, it has commonly been associated with the development of a low flow state secondary to the presence of either hypoplastic left heart (22), patent ductus arteriosus, polycythemia, or the placement of catheters in the portal venous circulation or in the arterial circulation above the level of the mesenterics (11). The intestinal lumen of neonates and the mural blebs characteristic of pneumatosis intestinalis, a frequent finding in necrotizing enterocolitis, contain $\mathrm{H}_{2}(9)$, apparently resulting from bacterial fermentation of malabsorbed carbohydrate. Indeed, $\mathrm{H}_{2}$ production and excretion occurs in neonates following institution of feedings $(16,21)$, and the magnitude of $\mathrm{H}_{2}$ excretion in breath is greater in premature than in term infants, presumably reflecting immaturity of carbohydrate absorption (21).

Newborns, particularly the premature, therefore are a population on well-defined dietary intake in whom carbohydrate substrate appears to be continually available for $\mathrm{H}_{2}$ production by bacteria with subsequent $\mathrm{H}_{2}$ excretion in breath. Although speculative, it is possible that serial monitoring of breath $\mathrm{H}_{2}$ excretion in the high-risk neonate, serving as his own control, may indicate the development of enteric hypoperfusion. The accuracy and sensitivity of this approach, suggested by the demonstration that breath $\mathrm{H}_{2}$ excretion reflects canine intestinal ischemia, requires validation. These data also demonstrate that diminution of mesenteric perfusion inhibits excretion of $\mathrm{H}_{2}$ by the respiratory pathway, which accounts for elimination of $14 \%$ of total $\mathrm{H}_{2}$ production in human adults (12). Intraluminal distention has been previously shown to interfere with intestinal blood flow (8). It is possible that impedance of $\mathrm{H}_{2}$ transport from the intestinal lumen may further compromise the mesenteric circulation in infants with low flow states.

\section{REFERENCES AND NOTES}

1. Barton, R. W. Reynolds, D. G., and Swan, K. G.: Mesenteric circulatory responses to hemorrhagic shock in the baboon. Ann. Surg.. 175: 2044 (1972).

2. Bond, J. H., and Levitt. M. D.: Use of breath hydrogen $\left(\mathrm{H}_{2}\right)$ in the study of carbohydrate absorption. Am. J. Dig. Dis., 22: 379 (1977).

3. Bond, J. H., Levitt, D. G., and Levitt, M. D.: Quantitation of countercurrent exchange during passive absorption from the dog small intestine. J. Clin. Invest., 59: 308 (1977).

4. Cahill, J. M., Strieder, D. J., and Byrne, J. J.: Lung function in shock. Am. J. Surg., 110: 324 (1965).

5. Calloway, D. H., and Murphy, E. L.: The use of expired air to measure intestinal gas formation. Ann. N. Y. Acad. Sci., 150: 82 (1968).

6. Calloway, D. H., Murphy. E. L.. and Bauer. D.: Determination of lactose intolerance by breath analysis. Am. J. Dig. Dis., 14: 811 (1969).

7. Corday, E.. Irving, D. W.. Gold, H., Bernstein, H., and Skelton, R. B. T.: Mesenteric vascular insufficiency: intestinal ischemia induced by remote circulatory disturbances. Am. J. Med., 33: 365 (1962).

8. Dragstedt. C. A., Lang, V. F., and Millet, R. F.: The relative effects of distention on different portions of the intestine. Arch. Surg.. 18: 2257 (1929).

9. Engel. R. R.: Studies of the gastrointestinal flora in necrotizing enterocolitis. In: Necrotizing Entercolitis in the Newborn Infant. pp. 66-71. Report of the SixtyEighth Ross Conference on Pediatric Research. Columbus, Ohio. 1975.

10. Haglund, V., and Lundgren. O.: Intestinal ischemia and shock factors. Fed. Proc., 37: 2729 (1978).

11. Kitterman, J. A.: Effects of intestinal ischemia. In: Necrotizing Enterocolitis of the Newborn Infant. pp. 38-44. Report of the Sixty-Eighth Ross Conference on Pediatric Research. Columbus, Ohio, 1975.

12. Levitt. M. D.: Production and excretion of hydrogen gas in man. N. Engl. J. Med., 281: 122 (1969).

13. Levitt, M. D., and Donaldson, R. M.: Use of respiratory hydrogen $\left(\mathrm{H}_{2}\right)$ excretion to detect carbohydrate malabsorption. J. Lab. Clin. Med., 75: 937 (1970).

14. Levitt. M. D., and Levitt. D. G.: Use of inert gases to study the interaction of blood flow and diffusion during passive absorption from the gastrointestinal tract of the rat. J. Clin. Invest., 52: 1852 (1973).

15. Lowery, B. D., and Sugg, J. H.: Pulmonary dysfunction after shock and trauma. In: pp. 415-433. L. B. Hinshaw, B. G. Cox: The Fundamental Mechanisms of Shock. (Plenum Press, New York, 1972).

16. MacLean, W. C., and Fink, B. B.: Lactose malabsorption by premature infants: magnitude and clinical significance. J. Pediatr.. 97: 383 (1980).

17. Metz, G., Jenkins, D. J. A., Peters, T. J., Newman, A., and Blendis, L. M.: Breath hydrogen as a diagnostic method for hypolactasia. Lancet, $1: 1155$ (1975).

18. Newcomer, A. D., McGill, D. B., Thomas, P. J., and Hofmann, A. F.: Prospective comparison of indirect methods for detecting lactase deficiency. N. Engl. J. Med., 293: 1232 (1975).

19. Norlen, K.. Rentzhog, L., and Wikstrom, S.: Regional and central hemodynamics during segmental ischemia of the small intestine in the rat. Eur. Surg. Res., 10: 246 (1978).

20. Perman, J. A., Barr, R. G., and Watkins, J. B.: Sucrose malabsorption in children: noninvasive diagnosis by interval breath hydrogen determination. J. Pediatr., 93: 17 (1978).

21. Perman, J. A., Waters, L. A., Heldt, G. P., and Rosental, E.: Carbohydrate absorption in premature infants. Gastroenterology, 76: 1216 (1979).

22. Polin, R. A., Pollack. P. F., Barlow, B., Wigger, H. J., Slovis, T. L.. Santulli, T. V., and Heird, W. C.: Necrotizing enterocolitis in term infants. J. Pediatr., 89 : 460 (1976).

23. Richards, C. H.. Wolf, S., and Wolff, H. G.: The measurement and recording of gastroduodenal blood flow in man by means of a thermal gradientometer. $J$. Clin. Invest., 21: 551 (1942).

24. Selkurt, E. E., Rothe, C. F.,. and Richardson, D.: Characteristics of reactive hyperemia in the canine intestine. Circ. Res., 15: 532 (1964). 
25. Smith, L. L., Reeves, C. D., and Hinshaw, D. B.: Hemodynamic alterations and regional blood flow in hemorrhagic shock. In: L. C. Mills, J. H. Moyer: Shock and Hypotension: Pathogenesis and Treatment. pp. 373-384 (Grune \& Stratton, New York, 1965).

26. Strandness, D. E., and Sumner, D. S.: Measurement of arterial and venous pressure. In: Hemodynamics for Surgeons. pp. 21-30. (Grune \& Stratton, New York, 1975)

27. Welsh, J. D.: Colon blood flow. Am. J. Dig. Dis., 8: 614 (1963).

28. Wilson, G. J., and MacGregor, D. C.: The measurement of myocardial tissue gas tensions by mass spectrometry. Crit. Care. Med., 4: 248 (1976).

29. Dr. Perman is the recipient of NIH Research Career Development Award HD00297.

Copyright $(1) 1981$ International Pediatric Research Foundation, Inc. 0031-3998/81/1509-1229\$02.00/0
30. This work was presented in part at the meeting of the Western Society for Pediatric Research, Carmel, California, February 7-9, 1979.

31. The authors acknowledge the expert technical assistance of Siv Modler and Judith A. Jester and the invaluable advice of Dr. M. Michael Thaler in preparation of the manuscript.

32. Requests for reprints should be addressed to: Jay A. Perman, M.D. Department of Pediatrics, M650, University of California, San Francisco, CA 94143 (USA).

33. This research was supported by NIH Grant HDI2449 and Basil O'Connor Starter Research Grant 5-206 from March of Dimes Birth Defects Foundation.

34. Received for publication October 10, 1980.

35. Accepted for publication February 2, 1981.

Printed in U.S.A. 